\title{
XVIII. ON THE EXTERNAL ANATOMY OF THE INDIAN RAT FLEA (P. CHEOPIS), AND ITS DIFFERENTIATION FROM SOME OTHER COMMON FLEAS.
}

\author{
(Plates X to XII.)
}

In a previous paper (vol. vI. p. 486) the physiological anatomy of the mouth parts and alimentary canal of $P$. cheopis has been described. In the present paper we propose to give a detailed description of the external morphology.

For those who are not familiar with entomological nomenclature it is necessary briefly to detail the general structure of a flea.

\section{General Structure of a Flea.}

A flea has its body laterally flattened and presents for description head, thorax and abdomen.

Head. The shape of the head varies considerably in different species. It is firmly united behind to the thorax. Attached to the head antero-ventrally will be found the mouth parts. In some species of tlea, $P$. felis for example, a row of large dark, peg-like teeth or bristles is found around the antero-ventral margin of the head. We shall call these bristles the perioral comb of bristles (Plate XII).

A. deep groove will be noted on the antero-lateral surface of the head with its long axis lying obliquely downwards and backwards. In this groove (antennary pit), which divides the lateral surface of the head into two portions, the antenna lies (Plate $\mathrm{X}$ ).

An eye (in those species which possess this organ) is situated on the anterior margin of the antennary groove (Plate $\mathrm{X}$ ).

A number of bristles are found over the surface of the head, the number and arrangement of these bristles being useful in distinguishing. the species. 
Thorax. The thorax consists of three segments jointed together, and very freely movable on one another. The anterior segment is known as the prothorax, the middle segment the mesothorax, and the posterior segment the metathorax.

In connection with the mesothorax and metathorax certain chitinous lateral plates are recognised. The exact homology of these plates is disputed, and the names applied to them differ so greatly that it would serve no useful purpose to describe them here. It will suffice to mention a large lateral plate (Plate X, $q$ ) attached to the metathorax, known by some as the squama aliforme (Tiraboschi), and by others as the metathoracic epimeron (Rothschild). This plate passes backwards over the abdomen and may readily be mistaken for a portion of an abdominal segment.

Numerous bristles, arranged in one or two vertical rows, are found on each segment of the thorax. In some species, Ceratophyllus fasciatus for example, a row of large teeth, similar to those surrounding the mouth parts in $P$. felis, is found along the posterior border of the prothorax (Plate XII). We shall call this row of large bristles the prothoracic comb of bristles. In some other species a similar comb is found on other segments of the thorax and even on the abdomen.

To each segment of the thorax a pair of legs is attached. Each leg is made up of the following parts; (1) a coxa, (2) a trochanter, (3) a femur, (4) a tibia, (5) a tarsus, the latter consisting of five segments (Plate IX, $\delta^{\prime}$ ). To the distal extremity of the last segment of each tarsus two claws are attached. The arrangement of the bristles on the various segments of the legs is of specific importance. In distinguishing the species much stress has been laid on the relative lengths of the various segments of the tarsus in the fore, mid, and hind legs.

Abdomen. The abdomen is made up of 9 segments (Plate XI), each segment consisting of a dorsal portion or tergum (tergite of Rothschild) and a ventral portion or sternum (sternite of Rothschild).

One or two vertical rows of bristles are present on each of the anterior tergites, while only a single row is found on some of the sternites.

If the dorsal margin of the abdomen is followed backwards, the observer will come to one or more large bristles which arise immediately anterior to and overhang a peculiar oval or heart-shaped organ. This organ is dotted over with small circular markings, from the centre of each of which a fine long hair projects, while surrounding each circle a number of more minute hairs will be found. This organ has been called 
the pygidium and the large bristles, which overhang it, "the antipygidial bristles" (Plate $\mathrm{X}$ ). The number and relative length of these bristles are of great utility in distinguishing the various species of fleas (Plate XII). Immediately posterior to the pygidium the genital organs and their addenda can be made out. These organs of course differ in the male and female.

\section{Determination of Sex.}

Male fleas are readily distinguished from female fleas as follows, (Plate $\mathrm{X})$ :-

(a) The male flea is usually smaller than the female; $(b)$ the shape of the abdomen differs; and (c) within the abdomen of the male there are curved chitinous plates connected with the sexual organs which are wanting in the female.

As regards (b) the length of the dorsal margin of the abdomen in the male is considerably shorter than the ventral margin, so that the abdomen is tail tilted, as it were, while in the female the dorsal edge of the abdomen is quite as long as the ventral edge. Within the abdomen of the female, in place of the coiled chitinous plates found in the male, oval-shaped eggs can often be made out.

\section{Determination of Species.}

The exact species to which a particular flea belongs is usually determined by a careful examination of the generative organs and their appendages, but for practical purposes, when living fleas have to be identified, this method is impossible, in that it involves a careful dissection of the various parts which are more or less intimately associated with and lie concealed within the posterior abdominal segments.

As has already been remarked the abdomen consists of 9 segments. Considerable difference of opinion exists among entomologists as to the homology of these various segments, especially regarding the posterior segments. We have found it necessary to investigate this matter in connection with the description of $P$. cheopis.

It has generally been held that the first abdominal segment is represented only by the tergite and that the sternite of this segment is wanting, being fused with the squama aliforme, a portion of the metathoracic segmenti. As will be seen from the account given below, we

1 C. Tiraboschi, "Les rats, les souris et leur parasites cutanes," Arch. de Parasito. logie, vill. p. 220, 1904. 


\section{Reports on Plague Investigations in India}

are not able to agree with this assumption. We consider that the first abdominal sternite is the one which has up to the present been recognised as the second by those who believe that the first sternite has been fused to the metathorax. Our enumeration of the abdominal segments is shown in the accompanying diagrams (Plate XI, left half). It is, however, necessary to detail more carefully the arrangements in the three posterior segments, viz. the 7 th, 8 th and 9 th.

These segments are profoundly modified for sexual purposes and differ in the male and female.

The 7th abdominal tergite in both sexes bears the antipygidial bristles (Plate XI).

The 8th tergite differs markedly in the two sexes (Plate XI). In the male this tergite is very small, being only large enough to carry the stigmata or tracheal openings of the 8th abdominal segment, while in the female it is very greatly developed and covers over, not only a portion of the 9 th tergite, but also the whole of the 7 th, 8th and 9 th sternites and the anal and vaginal orifices ${ }^{1}$. The arrangement of the bristles on this tergite in the female is of importance in classification.

The 9th tergite in both sexes carries the pygidium and an anal flap (Plate XI). On this flap in the female a prominent bristle can readily be made out, arising from an elevated pyramidal tubercle. We shall call this bristle the pyramidal bristle. The relative length of this bristle compared with the length of the antipygidial bristle is of use in distinguishing the species of fleas (Plates $\mathrm{X}$ and XI).

Passing now to the corresponding posterior sternites we see that the seventh abdominal sternite differs in the male and female. In the male this sternite (previously generally recognised as the 8th sternite) is largely developed. It bears on its surface a number of large bristles, the arrangement of these bristles varying in different species. This sternite conceals more or less completely the 8th and 9th sternites and the end of the penis (Plates $\mathrm{X}$ and $\mathrm{XI})^{2}$. In the female the 7 th sternite is a small, delicate, chitinous plate which forms the ventral wall of the external genital aperture. This plate contains also the opening of the duct to the spermatheca. Considerable care has to be taken to demonstrate this delicate sternite which, as far as we can ascertain from the literature available, has not been recognised by others who have worked at the subject. The position which it occupies relatively to the adjacent tergite and sternites can be understood from an examina-

1 The parts have been separated out in the figures.

${ }^{2}$ The penis has not been drawn in the plates. 
tion of Plate XI which gives both a lateral (I) and a posterior (II) view of the abdominal segments of a female. No bristles are found on this sternite.

The 8 th abdominal sternite in the male and female is split mesially into two portions (Plate $\mathrm{XI}$, right hand top figure).

In the male the 8th sternite corresponds to Rothschild's "boomerangshaped organ," and also generally called by him the 9 th sternite. The position of this sternite can readily be made out from Plates $X$ and XI. Rothschild has drawn attention to it, as being of importance in distinguishing fleas.

In the female the 8 th sternite, as is the case in the male, is split into two symmetrical portions, the two delicate flaps of chitin closing in postero-ventrally, more or less completely, the entrance to the oviduct (Plate XI, II). These flaps can be moved outwards and backwards during ovulation. The 9 th sternite in the male has been called "the clasper." It is divided into two symmetrical portions completely separated from one another (Plate XI, top figure to the right). Certain portions of the clasper have received distinguishing names from Wagner and Rothschild, such as "the movable finger," "the immovable finger," and the "manubrium."

The 9th sternite in the female lies immediately below the anal flap of the 9 th tergite and forms the lower boundary of the anal orifice. It is bilaterally symmetrical but is not split into two portions like the homologous sternite in the male (Plates $\mathrm{X}$ and $\mathrm{XI}$ ).

\section{Description OF $P$. cheopis.}

We shall pass on now to a more detailed description of $P$. cheopis.

Head. Attention has already been drawn to the maxillary palps in the paper on the anatomy of the mouth parts (Plate X). As some stress has been laid on the measurements of the various segments of the palps in the differentiation of species, we have measured these segments in the case of twelve fleas of this species. The average measurements and the extreme variations in the length of each of the four segments are given in the following table. The measurements are given in $\mu$ (microns).

1st or basal segment

Average

$64 \cdot 7$

2nd segment

3rd segment

4th or distal segment
71.7

$51 \cdot 4$

$91 \cdot 9$

$\begin{array}{cc}\text { Maximum } & \text { Minimum } \\ 74 & 56 \\ 86 & 62 \\ 67 & 46 \\ 120 & 78\end{array}$


A well-marked eye is present, situated on the anterior and inferior margin of the antennary groove (Plate $\mathrm{X}$ ).

The shape of the antennary groove is different in the male and female. In the former it arises very near the summit of the head and is very much larger and longer than in the female (Plate $\mathrm{X}$ ). It thus comes that the eye in the male lies somewhat lower in relation to the antennary groove, than in the female. Along the upper and posterior margin of the antennary groove, in the male only, a row of 13 small bristles will be found. Immediately posterior to the upper end of the antennary groove in the male a second groove (dorsal groove Plate $\mathrm{X}$ ) will be noted, running along the whole of the narrow dorsal surface of the head as far back as its junction with the thorax. During copulation the male flea lies beneath the female and it is in this groove that the ventral surface of the anterior segments of the abdomen of the female lie during the act.

Bristles on the head. In both sexes the following arrangement of bristles on the head is noteworthy (Plate X). (1) One bristle (oral bristle) is situated on the antero-lateral surface of the head immediately above and external to the maxillary palp. (2) One bristle (ocular bristle) arises slightly anterior to and almost on a level with the upper margin of the eye. (3) Immediately behind the antennary groove a series of three bristles form a line running parallel with the groove and meeting another series of bristles which forms a vertical line passing upwards along the posterior margin of the head. These lines of bristles meet at an angle in a bristle which is common to both rows.

Thorax. On the thorax three vertical rows of bristles are found, one row along the posterior border of the tergite of each segment (Plate $\mathrm{X}$ ). A double row of bristles is to be noted on the squama aliforme (Plate $X, q)$. These bristles, since they appear to lie over the abdomen, should be distinguished from those found on the abdominal segments.

Legs. The arrangement of the bristles on the legs is characteristic.

On the fore leg (Plate $\mathrm{X})$ : on the external surface of the coxa a large number of bristles is found. There are no bristles on the internal surface of this segment. A number of small bristles are found on the outer surface of the femur, together with some larger bristles, both in front and behind, at the lower end of the segment. The tibia is furnished with a number of large stout bristles.

On the middle leg (Plate $\mathrm{X}$ ) a few bristles occur along the anterior margin of the coxa. A few bristles are also found on the trochanter. A single row of about six bristles is found on the outer

Journ. of Byg. viI 
surface of the femur, in addition to a row of bristles along the posterior border. This latter row terminates at the distal extremity in two curved bristles, one of which is considerably larger than the other. The tibia is furnished with a large number of stout bristles.

On the hind leg (Plate $\mathrm{X}$ ) the outer surface of the coxa is covered with a number of bristles, especially its anterior portion. On the internal surface of this segment a curious row of small bristles, four to six in number, forms a line passing obliquely across the anterior portion of the segment (not shown in the Plate). A number of bristles are found on the trochanter. Along the posterior border of the femur a double row of small bristles is arranged, while on the external surface a row of six bristles is found and on the anterior edge two bristles are noteworthy. The tibia, as on the other legs, is furnished with a number of very large stout bristles.

The arrangement of the bristles in the five tarsal segments of all the legs can be recognised from the drawings.

A number of measurements have been made of the lengths of the femur, tibia and tarsal segments of 12 specimens. The maximum, minimum, and average length of each segment is recorded in the following tables. In giving these measurements it is well to remark that they were made from specimens which had been dehydrated and cleared.

The measurements do not represent the length of the longest diameter of each segment, but the length between the proximal and distal joints of each segment. The measurements are given in microns.

\begin{tabular}{|c|c|c|c|}
\hline \multicolumn{4}{|c|}{ Fore leg. } \\
\hline Segments & Average & Maximum & Minimum \\
\hline Femur & $233 \cdot 5$ & 260 & 220 \\
\hline Tibia & $161 \cdot 8$ & 180 & 130 \\
\hline 1st or proximal tarsal segment & $45 \cdot 3$ & 56 & 38 \\
\hline 2nd tarsal segment & $50 \cdot 9$ & 56 & 46 \\
\hline 3rd tarsal segment & $39 \cdot 4$ & 40 & 30 \\
\hline 4th tarsal segment & $29 \cdot 6$ & 35 & 28 \\
\hline 5th or distal segment & $86 \cdot 9$ & 93 & 80 \\
\hline \multicolumn{4}{|c|}{ Mid leg. } \\
\hline Segments & Average & Maximum & Minimum \\
\hline Femur & $277 \cdot 2$ & 306 & 240 \\
\hline Tibis & $248 \cdot 5$ & 280 & 220 \\
\hline 1st or proximal tarsal segment & $78 \cdot 4$ & 93 & 64 \\
\hline 2nd tarsal segment & $109 \cdot 7$ & 118 & 80 \\
\hline 3rd tarsal segment & $61 \cdot 7$ & 80 & 52 \\
\hline 4th tarsal segment & $33 \cdot 5$ & 36 & 32 \\
\hline 5th tarsal segment & $94 \cdot 2$ & 106 & 80 \\
\hline
\end{tabular}




$\quad$ Segments
Femur
Tibia
1st tarsal segment
2nd tarsal segment
3rd tarsal segment
4th tarsal segment
5th tarsal segment
Claw

Hind leg.

$\begin{array}{ccc}\text { Average } & \text { Maximum } & \text { Minimum } \\ 375 \cdot 8 & 400 & 340 \\ 349 \cdot 8 & 380 & 320 \\ 239 & 260 & 220 \\ 168 \cdot 3 & 184 & 146 \\ 91 \cdot 4 & 100 & 86 \\ 52 & 65 & 44 \\ 111 \cdot 7 & 120 & 100 \\ 73 \cdot 7 & 96 & 46\end{array}$

\section{Abdomen.}

On the lateral surface of the tergite of each segment vertical rows of bristles will be made out. In the case of the first segment there are two such rows of bristles, while, in the case of segments 2 to 7 inclusive, a single row only is found, each row being composed of eight bristles. On the sternites of the 2 nd to the 6 th segments the number of bristles differs in the male and female. In the male three bristles are found, in the female four in each row. The number of these bristles, however, is not constant, five or six bristles on some of the segments of the female having been seen.

Near the posterior border of the 7th abdominal tergite a single pair of very long antipygidial bristles can be made out, i.e., one on each side.

The pyramidal bristle of the 9th tergite in the female is shorter than the antipygidial bristle (Plate $\mathrm{X}, \stackrel{\wp}{q}$ ).

Of the remaining abdominal segments, the arrangement of the bristles on the 7 th sternite in the male and the 8th tergite in the female is of importance.

On the 7 th sternite of the male, in addition to a number of bristles scattered over its surface, two prominent bristles call for special notice. These bristles arise, one above the other, close to the posterior margin of the sternite and project almost vertically upwards. They are of course paired on the other half of the sternite (Plate $X, \delta^{\prime}$ ).

The 8th tergite in the female is covered with a large number of fairly large bristles: the number of these bristles varies slightly in different specimens, but the following rough arrangement can be made out (Plate $X, q$ ). Commencing from the lower end of the stigma, a series of bristles, increasing in size from above downwards, are 
observed. These bristles, numbering from four to five, form a line which passes vertically downwards. This line of bristles meets another row at a very obtuse angle. From four to six bristles are found in this latter row, which passes in an oblique direction downwards and slightly backwards to nearly the lower and anterior border of the tergite. Here it joins another prominent row, of from 10 to 14 bristles, which passes in a curved direction upwards and backwards along the inferior and posterior border of the tergite. In the space enclosed between these rows of bristles three or four other bristles are found. Towards the upper extremity of the curved ascending row of bristles and close to the posterior edge of the tergite a row of from six to eight small stout bristles is found. These bristles run along one side of the external opening of the oviduct.

The shape and arrangement of bristles on the 8th sternite in the male are best understood from an examination of Plate XI (right half). It is again necessary to point out that this sternite is the one which Rothschild calls the 9th sternite or the "boomerang organ." It is split into two entirely separate halves. The shape of each half is like the letter $L$, the vertical portion having a number of small bristles along its posterior margin and a few at its summit.

The 8th sternite in the female, as in the male, is split into two halves. These plates, which are devoid of bristles, are composed of very thin, almost colourless, chitin, and cover in the postero-inferior portion of the external genital aperture (Plate XI, I and II).

The 9 th sternite or clasper of the male is, as usual, characteristic of the species. The shape of the various parts of this sternite is best made out from Plate XI (right half).

The 9 th sternite in the female is a small flap, covered with numerous bristles (not shown in the figure), and forms the inferior boundary of the anal orifice (Plate XI, I and II).

\section{Differentiation of $P$. cheopis from a few other species.}

It has of course been impossible to examine every flea used in our experiments in such detail as has been given above. We have found it necessary, however, to go into this detail because several species of flea have been described which apparently very closely resemble the one described above. We would instance in this connection, P. pallidus (Tasch.), P. witherbyi (Roths.), P. nubius (Roths.), 
P. cleopatrae (Roths.), P. chephrensis (Roths.), P. gerbilli (Wag.), $P$. murinus (Tiraboschi), P. philippinensis (Schultze), etc., etc. We have examined a considerable number of the fleas ( $P$. cheopis) used in our experiments in great detail, and have found them always conforming to the above description.

A number of specimens have also been sent to Rothschild and they have been kindly identified by him as $P$. cheopis. For practical purposes, therefore, and in view of the fact that we have never met any species resembling, but distinct from, $P$. cheopis on the rats in Bombay or in the Punjab, we have adopted the following more simple method of distinguishing $P$. cheopis from certain other species we have met with in connection with our work. These other species of flea are :-

(1) Pulex irritans, the human flea.

(2) Ceratophyllus fasciatus, the flea commonly found on rats in Europe.

(3) Pulex felis, the cat and dog flea.

(4) Ctenopsylla musculi, commonly found on mice and rats in various parts of the world.

(5) Sarcopsylla gallinacea, a flea commonly found on birds.

All the above-mentioned fleas (Plate XII) have at one time or another been met with on rats. They all have well-developed eyes, except Ctenopsylla musculi. Of the remainder, Ceratophyllus fasciatus and P. felis have a prothoracic comb of bristles, and the latter a perioral comb. These bristles are absent in P. cheopis, P. irritans, and in Sarcopsylla gallinacea, but the latter flea is readily distinguished from the other two by its angular-shaped head and its largely developed mandibles.

We are thus left with $P$. cheopis and $P$. irritans, which can be differentiated from one another as follows:-

1. P. cheopis is small and light-coloured when compared with $P$. irritans.

2. The number of bristles on the head is greater in $P$. cheopis than in P. irritans, i.e. there is only one bristle on the posterior portion of the head in P. irritans, namely, the one which is found at the posterior and inferior angle of the head and corresponds in situation to the bristle which is common to the two rows of bristles found in this posterior portion of the head of $P$. cheopis. Moreover, the ocular bristle in $P$. cheopis is situated nearly on a level with the upper border of the eye, while in $P$. irritans it arises nearer to the lower margin of the eye. 
3. The antipygidial bristles in $P$. cheopis are longer than those found in $P$. irritans.

4. In the female $P$. cheopis the antipygidial bristle is longer than the pyramidal bristle of the 9th tergite, while in $P$. irritans the pyramidal bristle of the 9th tergite is as long as, if not longer than, the antipygidial bristle.

5. In the case of males the shape of the clasper at once distinguishes the fleas from one another.

6. The shape and size of the claws are different in the two species. They are small in $P$. cheopis and large in $P$. irritans. 


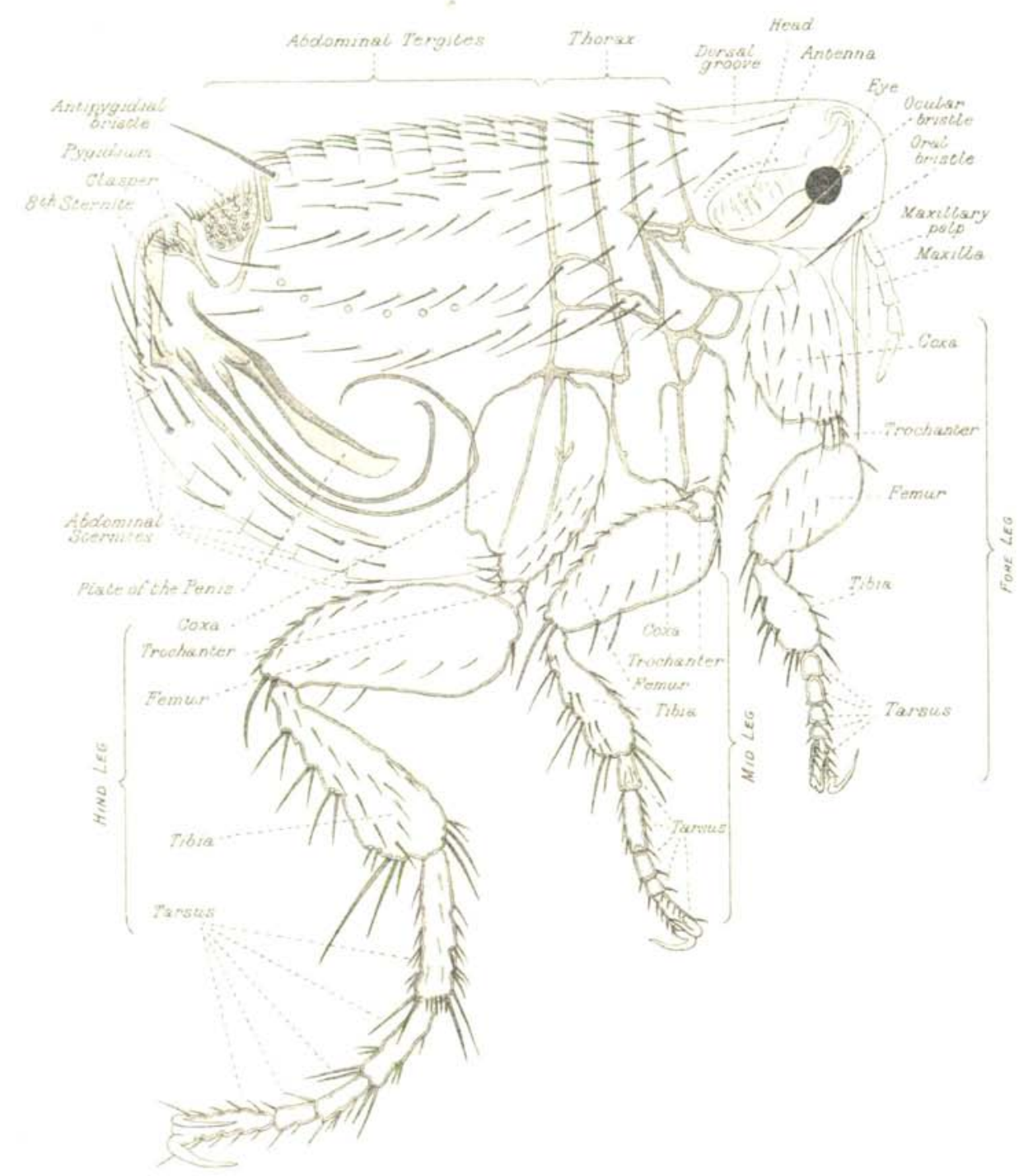

\& PULEX GHEOPIS. POTHSCHILD. 


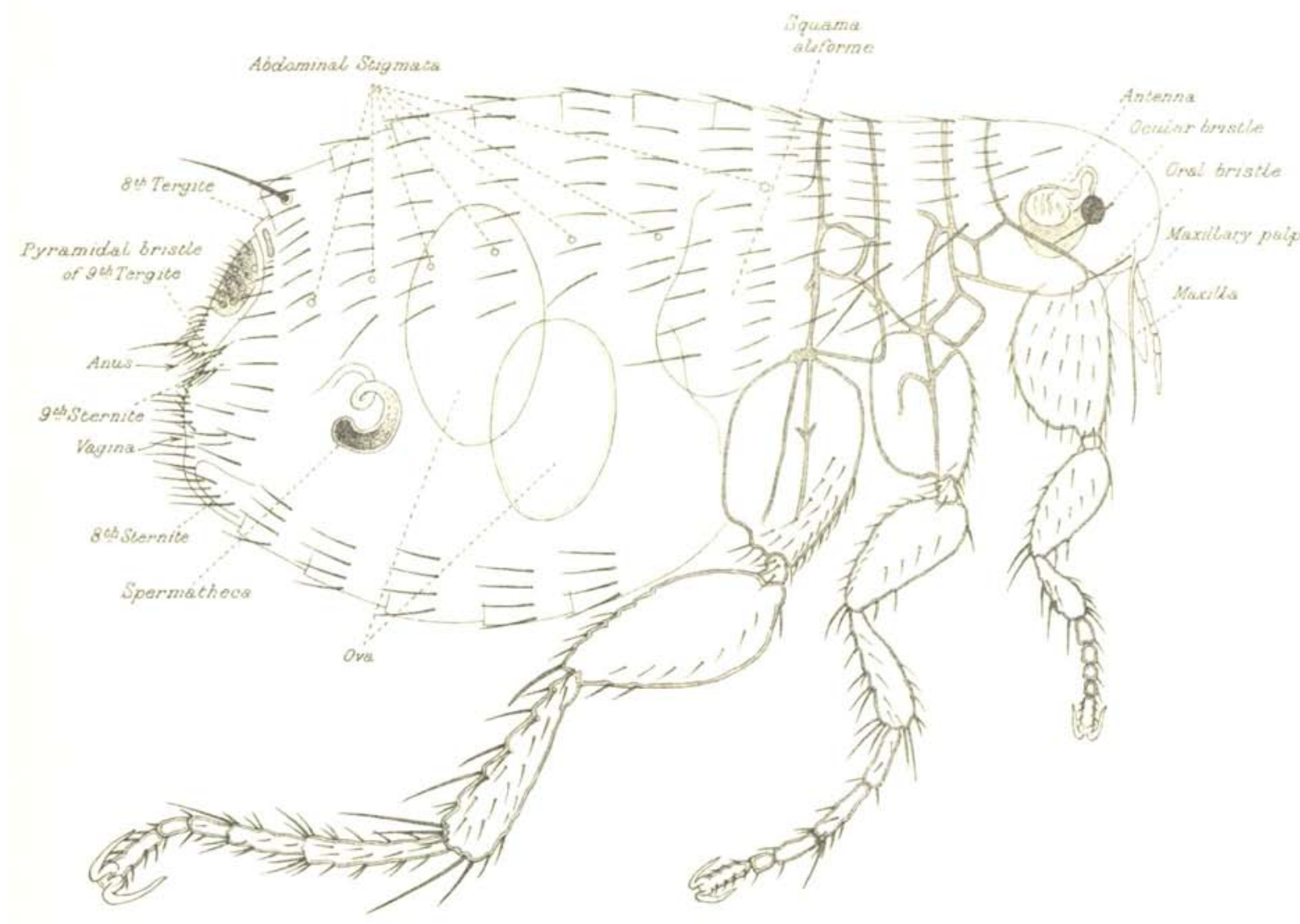

\& PULEX CHEOPIS, ROTHSCHILO 
JOURNAL OF HYGIENE, VOL.VII, PLAGUE NUMBER.

DIAGRAM OF THE ABDOMINAL

SEGMENTS OF MALE FLEA

Genvial apenture

Clasper or
get Siernice

\& shistornice

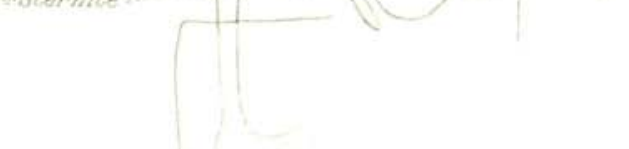

$74 \operatorname{sech}$

Ansl apercuns

के.

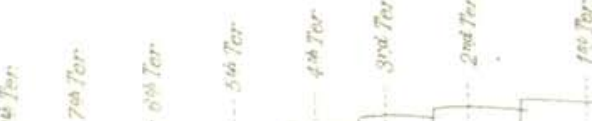
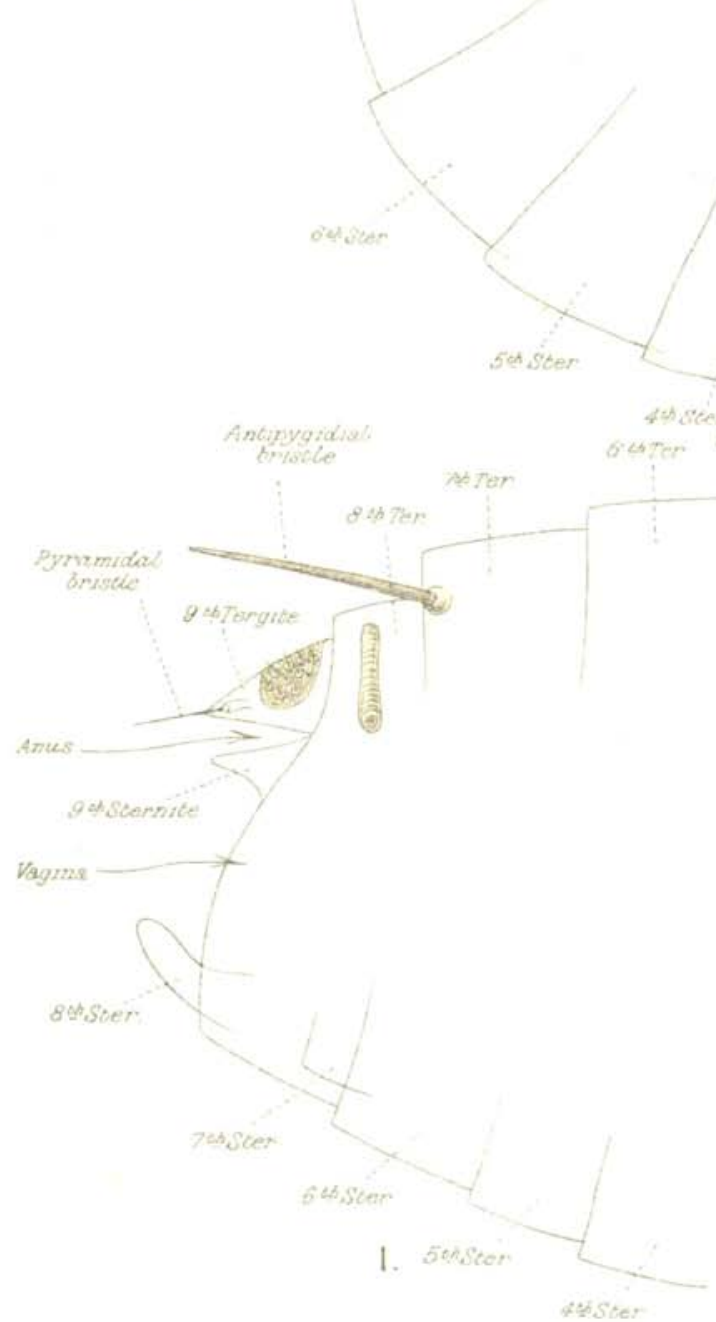

Gation soisien 2mister

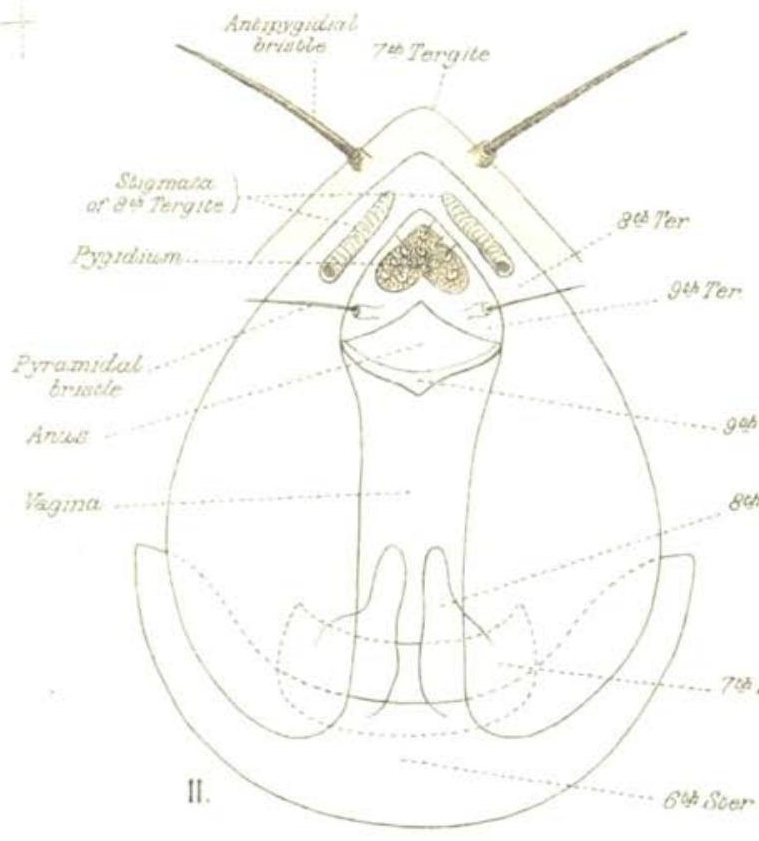

D A Turkhud YB Ed:m

DIAGRAM OF THE POSTERIOR ABDOMINAL SEGMENTS OF A FEMALE FLEA 


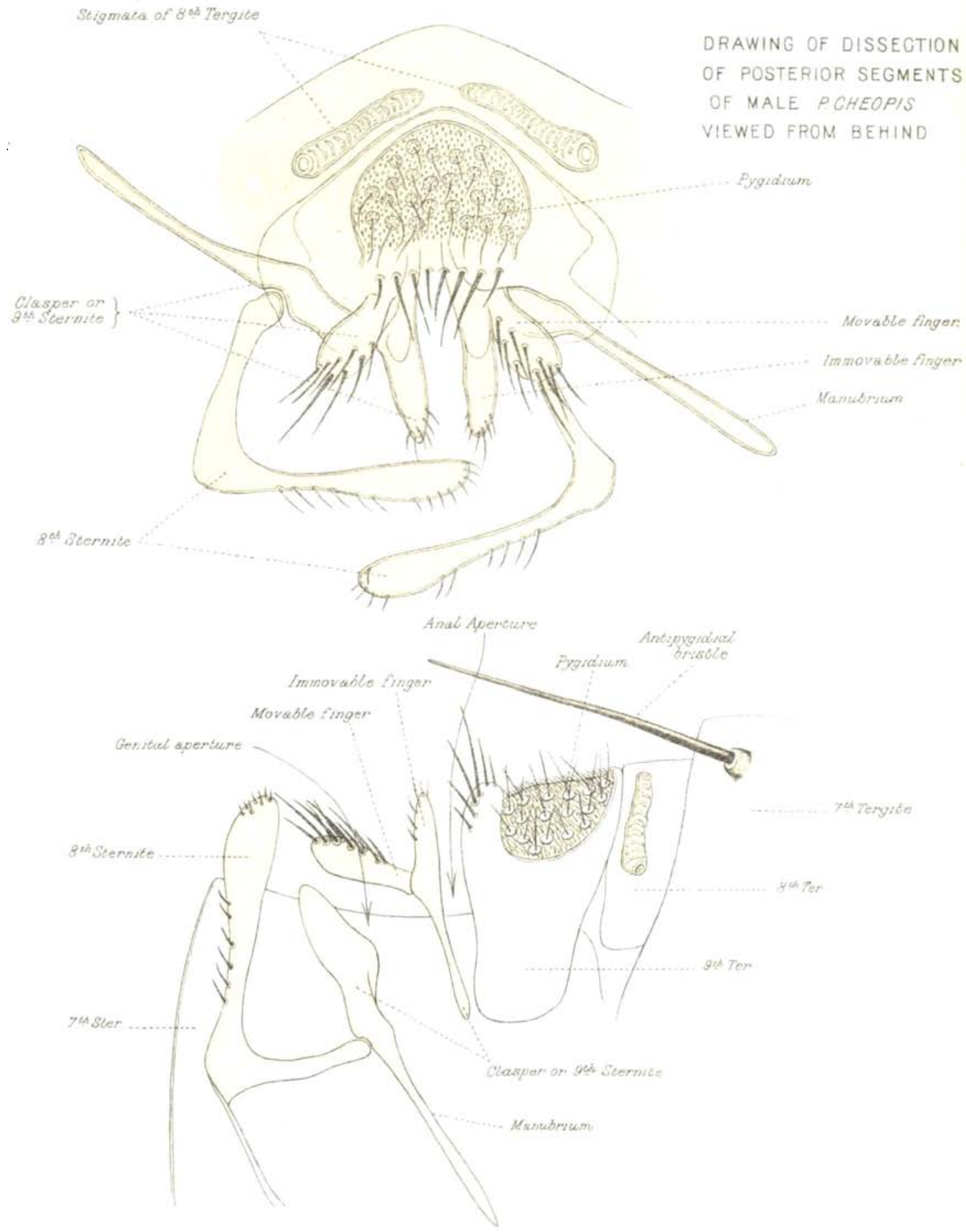

DIAGRAMATIC REPRESENTATION OF POSTERIOR ABDOMINAL 
o Pulex cheopis
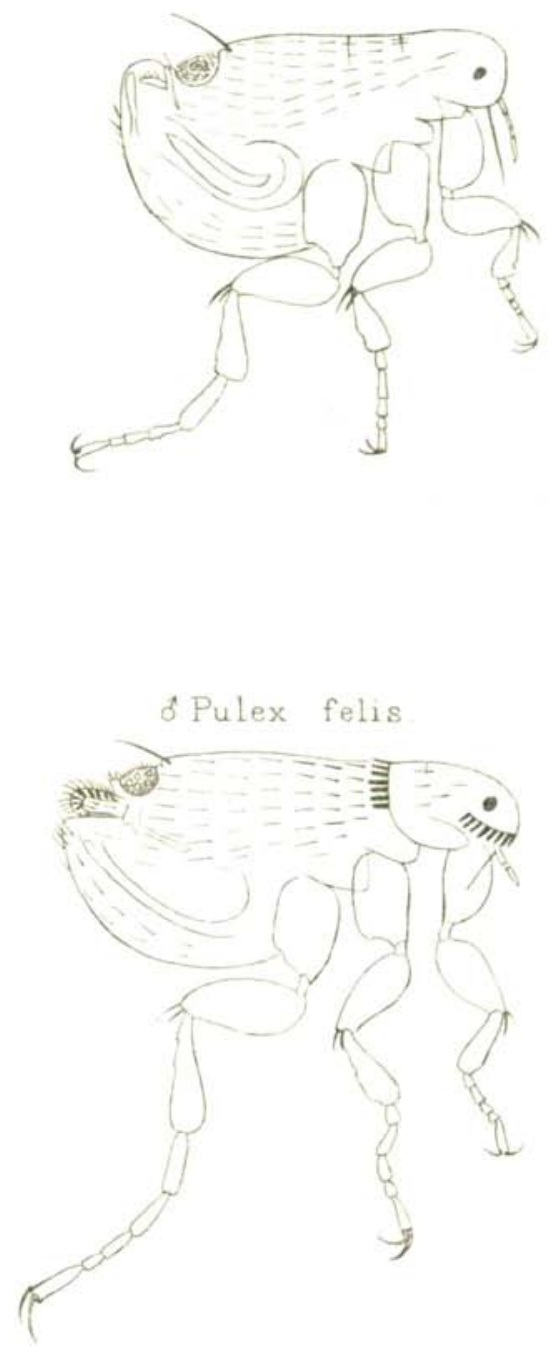

S Ctenopsylla musculi

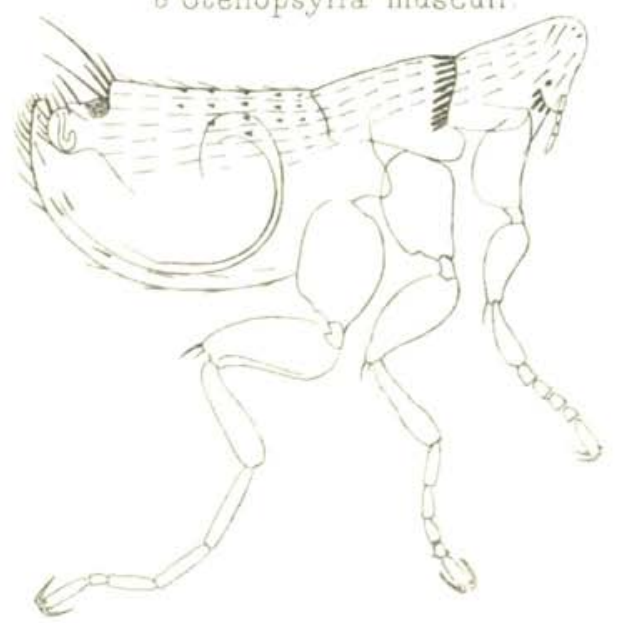

d Pulex irritans.

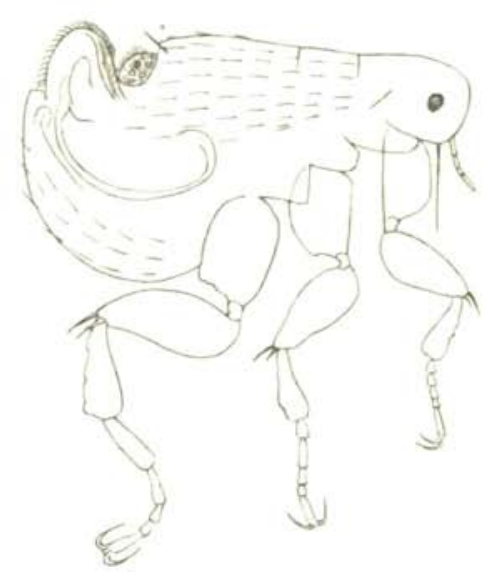

o Ceratophyllus fasciatus

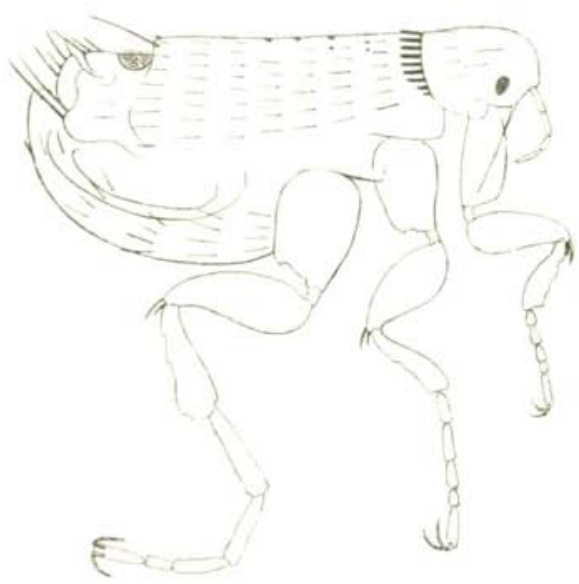

o Sarcopsylla gallinacea

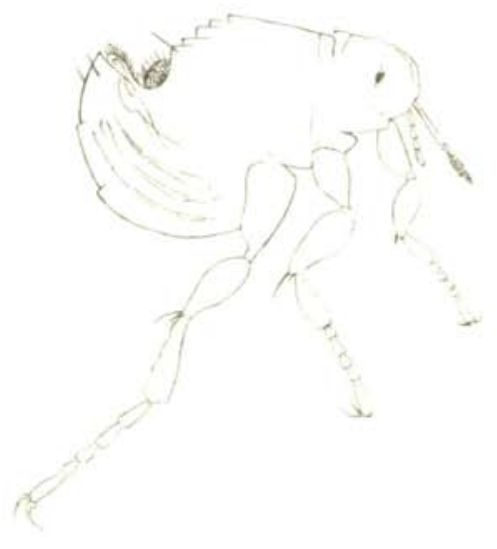

